\section{Targeting KRAS: Good, But Is It Good Enough?}

$\mathbf{R}_{\text {esente }}$ ecently, the FDA granted accelerated approval to sotorasib, a drug targeting a specific KRAS mutation (G12C) in non-small cell lung cancer. The approval was based on a study by Skoulidis et al, ${ }_{1}^{1}$ published in late June in The New England Journal of Medicine. This was a single-arm phase II trial involving 126 patients whose tumors carried this specific mutation, which occurs in about $13 \%$ of KRAS-driven lung cancers. In these patients, the response rate was $37.1 \%$, median progression-free survival was 6.8 months, and median overall survival was 12.5 months. During the short follow-up period, the median duration of response was 11.1 months.

Why was this a big deal? For years, I have worked beside brilliant scientists who studied cancer signaling pathways, and it was generally held that targeting KRAS was the "holy grail." In fact, the $\mathrm{NCl}$ put millions into establishing the "RAS Initiative" for the primary purpose of promoting the successful development of these drugs. KRAS had been considered "undruggable," but after the structure was studied from every possible angle, a weak link was identified and the race to come up with a drug began. The G12C mutation is just the beginning; theoretically, every possible mutation can eventually be targeted.

I expected this drug and others like it to be blockbusters, to "knock it out of the park," and to turn KRAS-driven cancers into mere shadows of their former selves. I expected this to work similar to how imatinib beat down chronic myelogenous leukemia. I knew better than to think every tumor would respondpreclinical studies showed that not all cell lines died out when you shut down the KRAS pathway-but I really did think that we would see transformative and durable benefit in more patients. Please don't get me wrong. The benefit seen with sotorasib is real and it's important. I have no issue with the accelerated approval, especially given the favorable safety profile; but I honestly expected more.

Responses occurred less frequently than observed with tyrosine kinase inhibitors approved for other driver mutations in lung cancer. I didn't expect that. Clearly, we need to know more. Would the results have been different in a patient population that had received much less previous therapy? Do the resistance mechanisms have an antidote? Are there other pathways that must also be suppressed when you target KRAS? The possibilities, of course, are endless, and I have no doubt that our thoracic oncology colleagues will sort this out over time.

I am also puzzled why this drug doesn't seem to work as well in other diseases in which KRAS mutations occur, like colorectal cancer. In an earlier phase I trial, the response rate was only $7.1 \%{ }^{2}$ This is another knowledge gap to fill.

Despite all these concerns, though, I consider this a watershed moment in the history of cancer therapy. Another victory for our patients! And I know more will come.

\section{References}

1. Skoulidis F, Li BT, Dy GK, et al. Sotorasib for lung cancers with KRAS p.G12C mutation. N Engl J Med 2021;384:2371-2381.

2. Hong DS, Fakih MG, Strickler JH, et al. KRAS ${ }^{\mathrm{G} 12 \mathrm{C}}$ inhibition with sotorasib in advanced solid tumors. N Engl J Med 2020;383:1207-1217. JNCCN@nccn.org or log into www.editorialmanager.com/JNCCN.

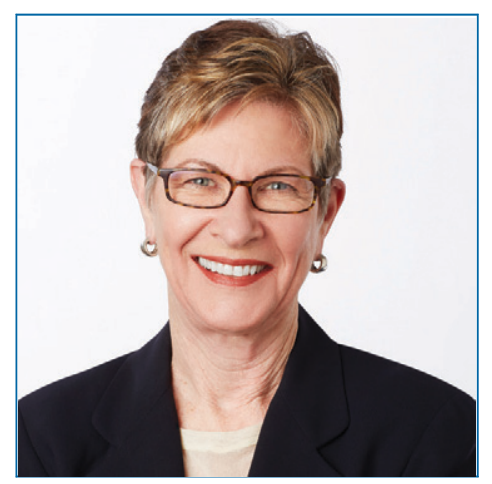

MARGARET TEMPERO MD

Margaret Tempero, MD, is a Professor of Medicine and Director of the UCSF Pancreas Center and editor-in-chief of JNCCN. Her research career has focused on pancreatic ductal adenocarcinoma, especially in the area of investigational therapeutics. Dr. Tempero has served on the ASCO Board of Directors and as ASCO President. She currently serves on the ASCO Conquer Cancer Foundation Board. She codirected the AACR/ASCO Methods in Clinical Cancer Research and taught this course and similar courses in Europe and Australia. She was founding Chair of the $\mathrm{NCl}$ Clinical Oncology Study Section and served as a member and Chair of the $\mathrm{NCl}$ Board of Scientific Counselors Subcommittee A. She is a member of the Scientific Steering Committee and Chair of the Clinical and Translational Study Section for the Cancer Prevention \& Research Institute of Texas. She is or has been on the Scientific Advisory Boards of the Lustgarten Foundation, the Pancreatic Cancer Action Network, the $V$ Foundation, The Alberta Canada Cancer Board, and the EORTC. She served as a member of the Oncology Drug Advisory Committee for the FDA. She has served as Deputy Director and Interim Director for the UNMC Eppley Cancer Center. She is Chief Emeritus of the Division of Medical Oncology at UCSF. She served as the founding Deputy Director and was later Director of Research Programs at the UCSF Helen Diller Family Comprehensive Cancer Center.

doi: 10.6004/jnccn.2021.0044

The ideas and viewpoints expressed in this editorial are those of the author and do not necessarily represent any policy, position, or program of NCCN. 